\title{
Acute psychosis after CPAP treatment in a schizophrenic patient with sleep apnoea-hypopnoea syndrome
}

\author{
E. Chiner, J.M. Arriero, J. Signes-Costa, J. Marco
}

\begin{abstract}
Acute psychosis after CPAP treatment in a schizophrenic patient with sleep apnoeahypopnoea syndrome. E. Chiner, J.M. Arriero, J. Signes-Costa, J. Marco. (C)ERS Journals Ltd 2001.

ABSTRACT: A 52-yr-old man with a residual phase of schizophrenia developed sleep apnoea-hypopnoea syndrome (SAHS). After five days of continuous positive airway pressure (CPAP) treatment, the patient developed an aggressive mood with incoherence, prominent hallucinations and agitation, and attempted to hit his relatives. He was finally admitted to the hospital with an acute psychotic episode. Withdrawal of CPAP, and neuroleptic treatment controlled the episode, and clinical symptoms of SAHS reappeared 10 days later.

Schizophrenia associated to sleep apnoea-hypopnoea syndrome has rarely been reported, but, to the authors' knowledge, the induction of a psychotic episode by continuous positive airway pressure treatment in a patient with sleep apnoea-hypopnoea syndrome and coexisting schizophrenia has never been previously reported.
\end{abstract} Eur Respir J 2001; 17: 313-315.
Pneumology Section, Hospital Universitari Sant Joan d'Alacant, Alicante, Spain.

Correspondence: E. Chiner Vives, Sección de Neumología, Hospital Universitari Sant Joan d'Alacant, Carretera Alicante-Valencia s/n, 03550 San Juan de Alicante, Spain.

Fax: 96-5658750

Keywords: Adverse effects

CPAP

psychosis

schizophrenia

sleep apnoea-hypopnoea syndrome

Received: June 151999

Accepted after revision July 142000
Patients with sleep apnoea-hypopnoea syndrome (SAHS) complain of neuropsychological deficits that suggest organic brain dysfunction, mainly related to the severity of hypoxaemia [1] or to sleep deprivation and chronic sleep fragmentation [2]. A neurotic profile characterized by depression, psychosocial withdrawal and hypochondriasis has been reported in SAHS patients [3]. Treatment with continuous positive airway pressure (CPAP) has been reported to improve psychological symptoms, psychosocial adjustment, daytime sleepiness [4] and daytime function [5], but it is not clear if CPAP ameliorates the cognitive deficits [6]. Schizophrenia associated to SAHS has rarely been referred $[7,8]$, but, to our knowledge, the induction of a psychotic episode by CPAP treatment in a patient with SAHS and coexisting schizophrenia has never previously been reported.

\section{Case report}

A 52-year-old man was submitted to outpatient Sleep Unit because of SAHS suspicion. Ten years ago he suffered psychotic symptoms: incoherence, hallucinations, delusions, progressive deterioration in social relations and a blunted affect, with three active moderate phases during the first five years. A diagnosis of episodic schizophrenia with interepisodic residual symptoms, undifferentiated type (F20.3x(295.92), DSM-IV) was established (criteria A characteristic symptoms, B social dysfunction, $\mathrm{C}$ duration $\geqslant 6$ months, D mood disorders excluded, E medical condition or drug abuse excluded) [9]. Chlorpromazine was administered and discontinued after clinical stability. The patient went into a residual phase with social isolation and marked lack of initiative. Three years before our evaluation he had gained weight and simultaneously began to experience progressive daytime sleepiness, thus limiting his daily activities and making him remain quietly at home. Severe snoring and breath pauses during sleep were reported by his wife. On physical examination, the patient was a drowsy obese male with enlarged tongue, body mass index $31 \mathrm{~kg} \cdot \mathrm{m}^{-2}$ and neck circumference $43 \mathrm{~cm}$. His Epworth Sleepiness Scale score was 19 .

Polysomnographic findings were: time in bed $356 \mathrm{~min}$; sleep latency $1 \mathrm{~min}$; total sleep time (TST) $286 \mathrm{~min}$; sleep efficiency $79 \%$; latency to stage 1, $1 \mathrm{~min}$; to stage 2, $22 \mathrm{~min}$; to stage 3,110 $\mathrm{min}$; to rapid eye movement (REM) stage $50 \mathrm{~min}$. Percentages of sleep referred to TST were: REM stage $3 \%$; stage $1,46 \%$; stage $2,48 \%$; stage $3,3 \%$; stage $4,0 \%$; apnoeahypopnoea index (AHI) 52; arousal index 36; baseline arterial oxygen saturation $\mathrm{Sa}_{\mathrm{a}} \mathrm{O}_{2} 95 \%$; minimal $\mathrm{Sa}_{\mathrm{a}} \mathrm{O}_{2}$ $81 \%$.

CPAP titration was carried out on a second night, normalizing the AHI at a pressure of $8 \mathrm{cmH}_{2} \mathrm{O}$. Polysomnographic data under CPAP (second part of the night) were: sleep efficiency $97 \%$; latency to stage 1 , $1 \mathrm{~min}$; to stage 2, $5 \mathrm{~min}$; to stage 3,100 min; to stage 4, 
$104 \mathrm{~min}$; to REM stage, $67 \mathrm{~min}$. Percentages of sleep stages referred to TST were: REM stage $13.5 \%$; stage 1 , $42 \%$; stage $2,35 \%$; stage $3,4.6 \%$; stage $4,5 \%$; AHI 1 ; arousal index 6; mean $\mathrm{Sa}_{\mathrm{a}} \mathrm{O}_{2} 92 \%$; minimal $\mathrm{Sa}_{2} \mathrm{O}_{2} 90 \%$. The graphic display of hypnogram and $\mathrm{Sa}_{\mathrm{a}} \mathrm{O}_{2}$ before and during CPAP is depicted in figure 1.

CPAP treatment was prescribed at home. Good adaptation and compliance were reported by his wife, with progressive disappearance of daytime sleepiness. However, after five days of treatment, the patient went into an aggressive mood with incoherence, prominent hallucinations and agitation, and attempted to hit his relatives. He was finally taken to hospital by the police and admitted with an acute psychotic episode. Withdrawal of CPAP, and neuroleptic treatment controlled
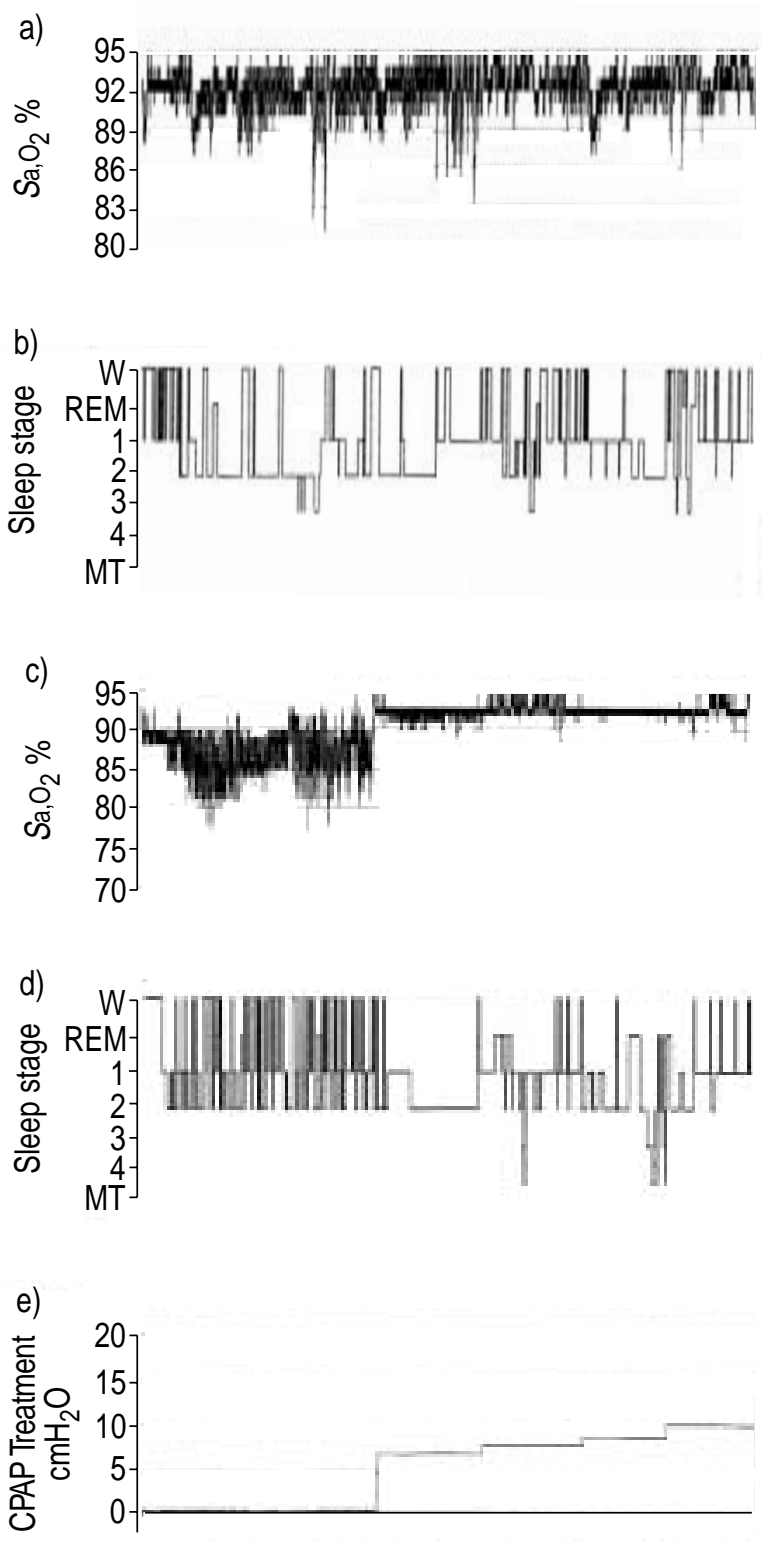

Fig. 1. - Arterial oxygen saturation $\left(\mathrm{S}_{\mathrm{a}, \mathrm{O}_{2}}\right)$ and hypnogram recordings before (a and b, respectively) and during (c and $\mathrm{d}$, respectively) continuous positive airway pressure (CPAP) treatment. Trace e) indicates CPAP treatment regime. REM: rapid eye movement sleep; MT: movement time. the episode, and clinical symptoms of SAHS reappeared ten days later. His wife refused a new CPAP treatment trial.

\section{Discussion}

Prevalence of sleep-related respiratory disorders in schizophrenic patients has scarcely been studied. ZARCONE and BENSON [7] reported that 14.5\% of male patients with schizophrenia had comorbid SAHS. In schizophrenic patients, TAKAHASHI et al. [8] in a study based only on oximetric data, reported a sleep-related respiratory disorder prevalence of $21.9 \%$ for males and $13.5 \%$ for females, not higher than that in a control group.

Schizophrenia and SAHS share several sleep disturbances such as the slow wave sleep deficit and shorter REM periods frequently interrupted by waking [7], but differ in other findings such as the marked increase in sleep onset latency reported in schizophrenia. Moreover, an abnormal REM rebound following REM sleep deprivation has been described in schizophrenia, although the mechanisms for this abnormality and its relation to symptoms remain unknown [10]. However, the slow wave sleep deficit and shortened REM sleep latency reported in schizophrenic patients have been criticised because most of these patients had been off neuroleptic medication for only a short period of time [11]. On the other hand, technical difficulties resulting from the lack of cooperation of schizophrenic patients in an acute phase may be an added problem. A decrease in levels of serotonin and its metabolites has been associated with a deficit in stage 4 sleep, suggesting that serotonin may modulate the amount of slow wave sleep in schizophrenia [12]. In this disease, cholinergic hyperactivity is related to negative symptoms, as a protective mechanism for the elevated dopaminergic activity and psychotic exacerbations [13]. Changes in dopaminergic transmission have been associated with REM sleep deprivation and the subsequent rebound of this stage [14]. A subpopulation of pedunculopontine neurons of the upper brainstem releasing acetylcholine, has been recognized as a critical modulator of REM sleep. Serotonin-mediated hyperpolarization of the cholinergic pedunculopontine neurons and afferent $\gamma$-aminobutyric acid (GABA)ergic dopamine-sensitive pathways, seems to be clinically relevant in the changes in quality, timing and quantity of REM sleep in schizophrenia [15]. These changes may be due, either to a different response of cells in the pedunculopontine neurons, or to an increase or decrease in the number of cells, or to an increased response to acetylcholine. Sleep onset latency and reduced sleep efficiency have been positively correlated with psychotic exacerbations [16].

In severe SAHS there is a marked disruption of the underlying neurophysiological mechanisms of sleep, which ceases with the REM rebound occurring in the first few days of CPAP treatment [17]. The present authors hypothesize that the patient had chronic sleep deprivation induced by SAHS, coexisting with the sleep disturbances of schizophrenia. The relative REM rebound and enhanced slow wave sleep, occurring 
after CPAP treatment for SAHS, may have increased dopaminergic activity or stimulated GABAergic pathways that modulate atonia versus cortical activation, favouring the psychotic attack. Withdrawal of CPAP may have "normalized" the equilibrium between the patient's cholinergic and dopaminergic systems, and, finally, the sleepiness of SAHS may have had a sedative effect.

In conclusion, psychiatric patients must be carefully followed during the first days of continuous positive airway pressure treatment, because the psychiatric disease may be masked by the severity of sleep apnoea-hypopnoea syndrome. Appropriate neuroleptic treatment should be administered in these patients before continuous positive airway pressure, in order to prevent the possible relapse of psychotic symptoms.

\section{References}

1. Findley LJ, Baarth JT, Powers DC, et al. Cognitive impairment in patients with obstructive sleep apnea and associated hypoxemia. Chest 1986; 90: 686-690.

2. Telakivi T, Kajaste S, Partinen $\mathbf{M}$, et al. Cognitive function in middle-aged snorers and controls: role of excessive daytime somnolence and sleep related hypoxic events. Sleep 1988; 11: 454-462.

3. Ramos MJ, Espinar J. Changes in psychopathological symptoms in sleep apnea patients after treatment with nasal continuous positive airway pressure. Intern $J$ Neuroscience 1992; 62: 173 - 195.

4. Sforza E, Krieger J. Daytime sleepiness after long-term continuous positive airway pressure (CPAP) treatment in obstructive sleep apnea syndrome. $J$ Neurol Sciences 1992; 110: $21-26$.

5. Engleman HM, Martin SE, Deary IJ, et al. Effect of CPAP therapy on daytime function in patients with mild sleep apnoea/hypopnoea syndrome. Thorax 1997; 52: $114-119$.

6. Engleman HM, Cheshire KE, Deary IJ, et al. Daytime sleepiness, cognitive performance and mood after continuous positive airway pressure for the sleep apnoea/hypopnoea syndrome. Thorax 1993; 48: 911 914.

7. Zarcone VP, Benson KL. Sleep and Schizophrenia. In: Kryger MH, Roth T, Dement WC, eds. Principles and Practice of Sleep Medicine, 2nd edition. Philadelphia: WB Saunders Company; 1994: pp 914-926.

8. Takahashi KI, Shimizu T, Sugita T, et al. Prevalence of sleep-related respiratory disorders in 101 schizophrenic patients. Psychiatry Clin Neurosci 1998; 52: 229-231.

9. American Psychiatric Association. Diagnostic and Statistical Manual of Mental Disorders: DSM-IV. 4th edition. (spanish version). Barcelona: Masson SA, 1995.

10. Zarcone VP, Azumi K, Dement W, et al. REM phase deprivation and schizophrenia: II. Arch Gen Psychiatry 1975; 32: $1431-1436$.

11. Lauer CJ, Screiber W, Pollmächer T, et al. Sleep in schizophrenia: a polysomnographic study on drugnaive patients. Neuropsychopharmacology 1997; 16: $51-60$.

12. Benson KL, Faull KF, Zarcone VP Jr. Evidence for the role of serotonin in the regulation of slow wave sleep in schizophrenia. Sleep 1991; 14: 133-139.

13. Tandon R, Greden JF. Cholinergic hyperactivity and negative schizophrenia symptoms. Arch Gen Psychiatry 1989; 46: 745-753.

14. Wojcik WJ, Radulovacki M. Selective increase in brain dopamine metabolism during REM rebound in the rat. Physiol Behav 1981; 27: 305-312.

15. Rye DB. Contributions of the pedunculopontine region to normal and altered REM sleep. Sleep 1997; 20: 757-788.

16. Zarcone VP, Benson KL. BPRS symptom factors and sleep variables in schizophrenia. Psychiatry Res 1997; 66: $111-120$.

17. Sullivan CE, Grunstein RR. Continuous Positive Airway Pressure in Sleep Disordered Breathing. In: Kryger MH, Roth T, Dement WC, eds. Principles and Practice of Sleep Medicine, 2nd edition. Philadelphia: WB Saunders Company, 1994; pp 694-705. 